\title{
Nova Técnica de END Baseada em Células Bacterianas para Deteç̧ão de Micro e Nano Defeitos Superficiais
}

\author{
Telmo G. Santos ${ }^{1}$, Patrick L. Inácio ${ }^{1}$, Alexandre A. Costa $^{1}$, R. M. Miranda ${ }^{1}$, Carla C. C. R. de Carvalho ${ }^{2}$
}

1 UNIDEMI - Departamento de Engenharia Mecânica e Industrial, Faculdade de Ciências e Tecnologia, Universidade Nova de Lisboa, Caparica, Portugal.

2 IBB - Instituto de Bioengenharia e Biociências, Departamento de Bioengenharia, Instituto Superior Técnico, Universidade de Lisboa, Portugal.

Recebido: 07 Jun., 2015

Aceito: 11 Jun., 2015

E-mails: telmo.santos@fct.unl.pt (TGS), ccarvalho@tecnico.ulisboa.pt (CCCRC)
Este é um artigo publicado em acesso aberto (Open Access) sob a licença Creative Commons Attribution Non-Commercia que permite uso, distribuiçăo e reproduçăo em qualq'uer meio, sem restriçöes desde que sem fins comerciais e que 0 trabalho original seja corretamente citado.
Resumo: Trabalhos recentes têm demostrado que filmes com células bacterianas (CB) podem ser usados como uma nova técnica de Ensaios Não Destrutivos (END) fiável para a deteção e caracterização de micro e nano defeitos superficiais. As CB podem ser usadas também numa perspetiva de caracterização da textura e topografia de superfícies. Esta nova técnica de END pretende explorar a intencionalidade e os atributos de vida das CB, nomeadamente: a sua reduzida dimensão, elevada capacidade de penetração, mobilidade, aderência, fluorescência, sensibilidade a campos elétricos e magnéticos, morte e reprodutibilidade. Neste trabalho descreve-se a metodologia usada para aplicação desta nova técnica de END, e é realizada a sua validação experimental em diferentes materiais com distintas morfologias de defeitos. Os resultados mostram que as CB permitem detetar eficazmente os defeitos presentes no bloco padrão Tipo1 ISO 3452-3 com 0,5 $\mu \mathrm{m}$ de espessura, defeitos do tipo fissura em soldadura laser de titânio, micro indentações em INCONEL, e nano indentações em ouro. Demonstrou-se assim a viabilidade desta técnica e o seu grande potencial para revelar defeitos em peças para diferentes aplicações industriais.

Palavras-chave: Microdefeitos superficiais; Células bacterianas; Rhodococcus erythropolis.

\section{A New NDT Technique Based on Bacterial Cells to Detect Micro and Nano Surface Defects}

\begin{abstract}
Recent work showed that bacteria cell films (CB) can be used as a new feasible non destructive testing technique (NDT), capable to detect and characterize micro and nano surface defects. Bacterial cells can also be used to characterize the surface texture and topography. This new NDT technique aims to exploit cells intentionality and life attributes, namely: their very small dimension, high penetration capacity, motility, adherence, fluorescence, sensitivity to electric and magnetic fields, death and reproducibility. This paper describes the methodology adopted to apply this technique, and the experimental validation in different materials with distinct defect morphologies. Results show that bacterial cells can effectively detect existing defects in ISO 3452-3 type 1 reference blocks with $0.5 \mu \mathrm{m}$ thick defects, crack type defects in laser welds in titanium, microindentations in INCONEL and nano indentations in gold. Thus, it was proven the feasibility of this technique, as well as its potential to detect defects in components for industrial applications.
\end{abstract}

Key-words: Surface microdefects; Bacteria cells; Rhodococcus erythropolis.

\section{Introdução}

Com o aparecimento de novas tecnologias de produção, como por exemplo a microfabricação, emerge um novo paradigma na área dos Ensaios Não Destrutivos (END) na deteção de defeitos com características superficiais de muito pequena dimensão. Contudo, a evolução tecnológica não tem sido acompanhada por um desenvolvimento consentâneo de novas técnicas de END. Recentemente, Santos et al. [1] propuseram uma nova técnica de END baseada na utilização de suspensões de células bacterianas (CB) para a deteção de micro e nano defeitos superficiais. A utilização de CB deriva da sua capacidade para aderir preferencialmente às irregularidades superficiais como rugosidades e fissuras. Contrariamente aos END por Líquidos Penetrantes (LP), as células bacterianas possuem atributos biológicos e intencionalidade, e desta forma pretendeu-se explorar algumas propriedades como a sua reduzida dimensão ( $1 \mu \mathrm{m})$, a elevada capacidade de 
penetração, a mobilidade, a aderência, a reprodutibilidade e morte. Além disso é possível corar CB com corantes fluorescentes e aproveitar a sua susceptibilidade a campos magnéticos e elétricos [2].

A metodologia de ensaio da nova técnica é semelhante à usada nos LP e nos ensaios com partículas magnéticas: as células bacterianas são depositadas sobre a superfície e deixadas penetrar nos defeitos. Durante este tempo de penetração podem ser utilizados campos magnéticos ou eléctricos visando promover a mobilidade e penetração das bactérias no defeito. Após esta etapa o excesso de bactérias pode ser removido por agentes bactericidas, luz ultravioleta ou por meios mecânicos. A visualização das bactérias nos defeitos pode ser feita por microscopia de fluorescência. Por fim um revelador (meio de crescimento) pode ser utilizado para aumentar a concentração das bactérias presentes nos defeitos, permitindo a identificação dos defeitos a olho nu.

Uma das dificuldades na deteção de micro e nano defeitos superficiais com líquidos penetrantes, está relacionada com o facto de alguns defeitos apresentarem uma baixa relação entre o volume e a área superficial $\left(\mathrm{V} / \mathrm{A}_{\text {sup }}\right)$ do defeito (Figura 1). Assim, pode ser mais difícil detetar defeitos com maior área superficial mas menos profundos (p.e. defeitos produzidos com um indentador), do que detetar defeitos do tipo fissuras, como as existentes no bloco padrão Tipo 1 ISO 3452-3 para avaliar a sensibilidade dos LP. Isso deve-se ao facto de a relação $\mathrm{V} / \mathrm{A}_{\text {sup }}$ ser 3 vezes menor no defeito tipo microindentação do que do defeito tipo fissura (Equações 1 e 2). Com efeito, na fase de remoção do excesso, é mais provável remover o líquido do interior do defeito no caso deste apresentar uma baixa relação $\mathrm{V} / \mathrm{A}_{\text {sup }}$.

Neste trabalho descreve-se a aplicação da nova técnica de END com CB em diferentes materiais com diferentes morfologias de defeitos. Os resultados mostram que as CB permitem detetar eficazmente os defeitos presentes no bloco padrão Tipo1 ISO 3452-3 com 0,5 $\mu \mathrm{m}$ de espessura, defeitos do tipo fissura em soldadura laser de titânio, micro indentações em INCONEL e nano indentações em ouro.

$$
\begin{gathered}
\frac{V}{A_{\text {sup }}}=\frac{l \cdot e \cdot h}{l \cdot e}=h \\
\frac{V}{A_{\text {sup }}}=\frac{\frac{l^{2} \cdot h}{3}}{l^{2}}=\frac{h}{3}
\end{gathered}
$$

\section{Metodologias de Aplicação da Técnica de END com Células Bacterianas}

\subsection{Metodologia genérica}

A metodologia de ensaio da nova técnica de END com células bacterianas é semelhante à utilizada no ensaio END com Líquidos Penetrantes, sendo constituída por 6 etapas. A primeira etapa consiste em identificar e limpar a zona a inspeccionar de modo a desobstruir os defeitos, para que na segunda etapa seja aplicada uma suspensão de células bacterianas e esta possa entrar nos defeitos. Uma vez aplicada a suspensão é necessário aguardar que as células bacterianas penetrem e adiram aos defeitos (terceira etapa), removendo-se o excesso da suspensão que não penetrou nos defeitos decorrido o tempo de penetração (quarta etapa). Segue-se a observação com microscópio da zona inspeccionada (quinta etapa) e a interpretação dos resultados (sexta etapa).
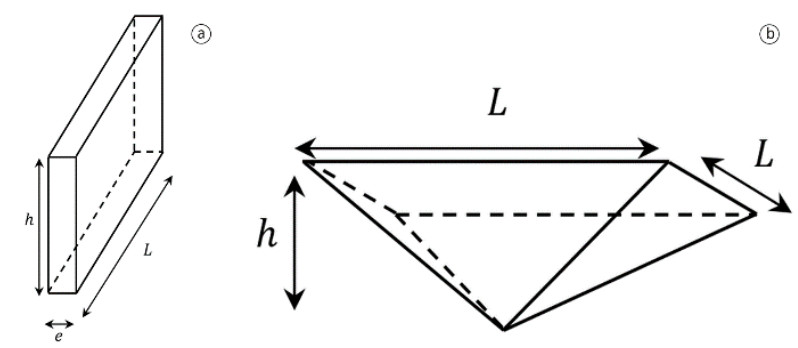

Figura 1. Morfologias de defeitos. (a) Defeito do tipo bloco padrão Tipo 1 ISO 3452-3. (b) Defeito produzido pelo microindentador Vickers. 
Concluído o ensaio procede-se à limpeza e esterilização da peça, sendo que a permanência da suspensão de células bacterianas na amostra não deve exceder dez minutos, para evitar a adesão irreversível das células bacterianas à superfície. Na Figura 2 é ilustrada a sequência de aplicação desta técnica de END com células bacterianas.

\subsection{Metodologia com campo magnético na fase de penetração}

As CB apresentam uma grande diversidade de propriedades que, em certos casos, podem ser aproveitadas de forma a criar uma vantagem numa determinada aplicação. Neste trabalho foram utilizadas CB sensíveis a campos magnéticos, e por isso utilizou-se esta característica para promover a mobilidade das bactérias na superfície do provete e a sua penetração nos defeitos (Etapa 3). Neste caso as CB podem ser consideradas como uma partícula ferromagnética que quando sujeitas a um campo magnético se movimentam-se na direcção do pólo magnético mais próximo. O campo magnético pode ser gerado com recurso a uma bobina ou com ímanes permanentes. Na Figura 3 é apresentado o protótipo funcional utilizado para aplicação de campo magnético com recurso a ímanes permanentes de neodímio na direcção horizontal e vertical.

O campo magnético ao qual as CB foram sujeitas durante o ensaio foi caracterizado com recurso a sondas de efeito de Hall. Foi utilizada uma sonda com três sensores posicionados nas direcções X,Y e Z e que permitiram medir a densidade de fluxo magnético, até $\pm 250 \mathrm{mT}$ ( \pm 2500 Gauss) com resolução de $0.1 \mathrm{mT}$ (1 Gauss). A sonda foi colocada na posição do provete e feita uma medição ao longo do tempo como representado na Figura 4.

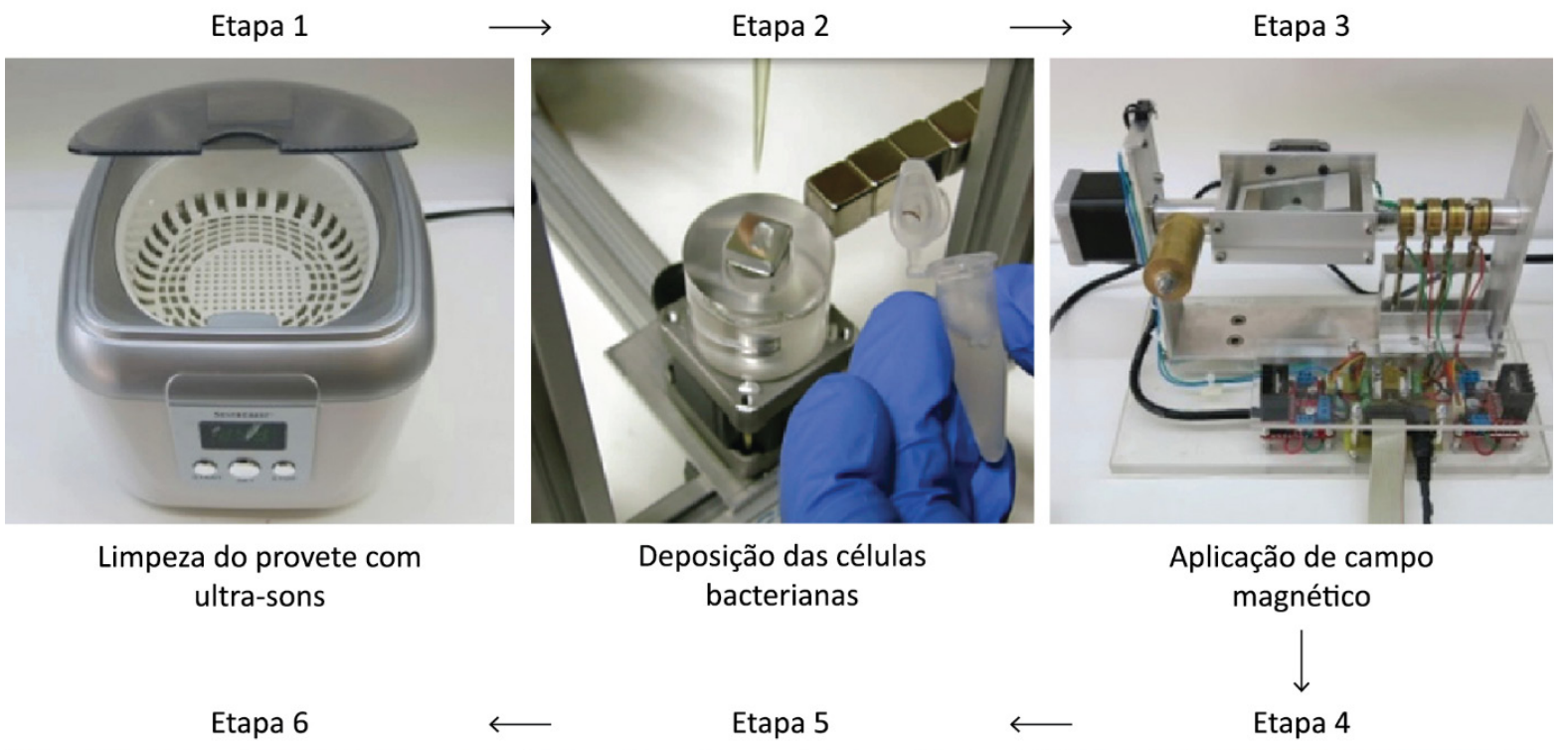

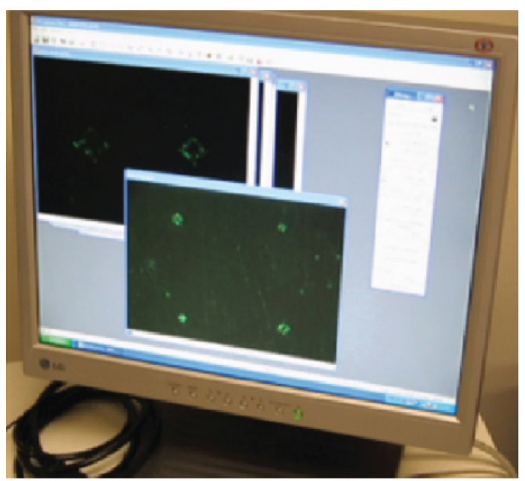

Interpretação dos resultados

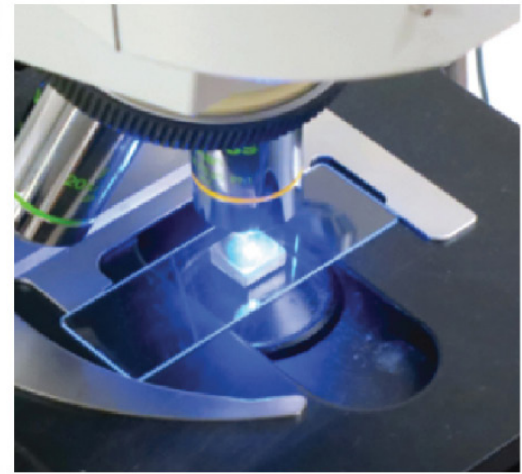

Observação com microscópio óptico

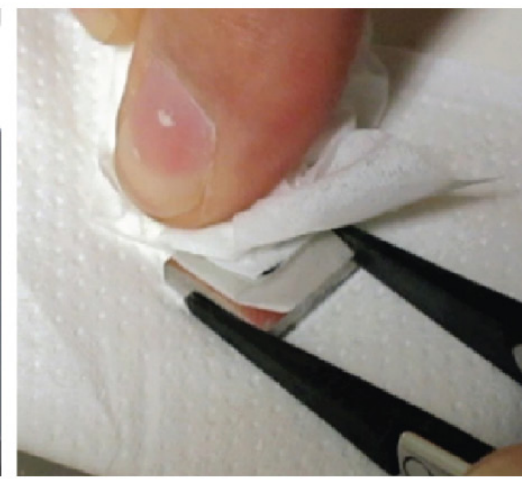

Remoção do excesso

Figura 2. Metodologia genérica da técnica de END com células bacterianas. 


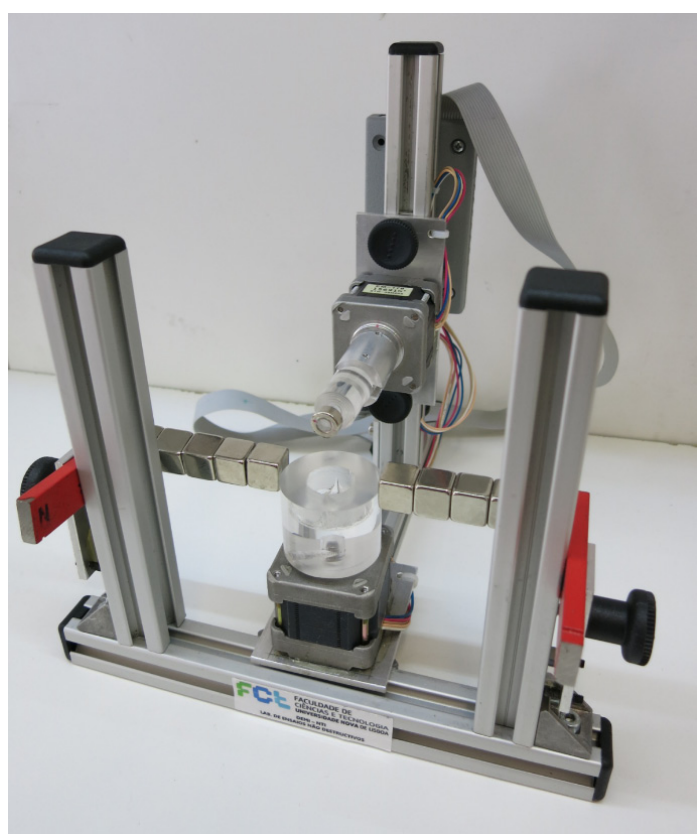

Figura 3. Equipamento para aplicação de campo magnético.
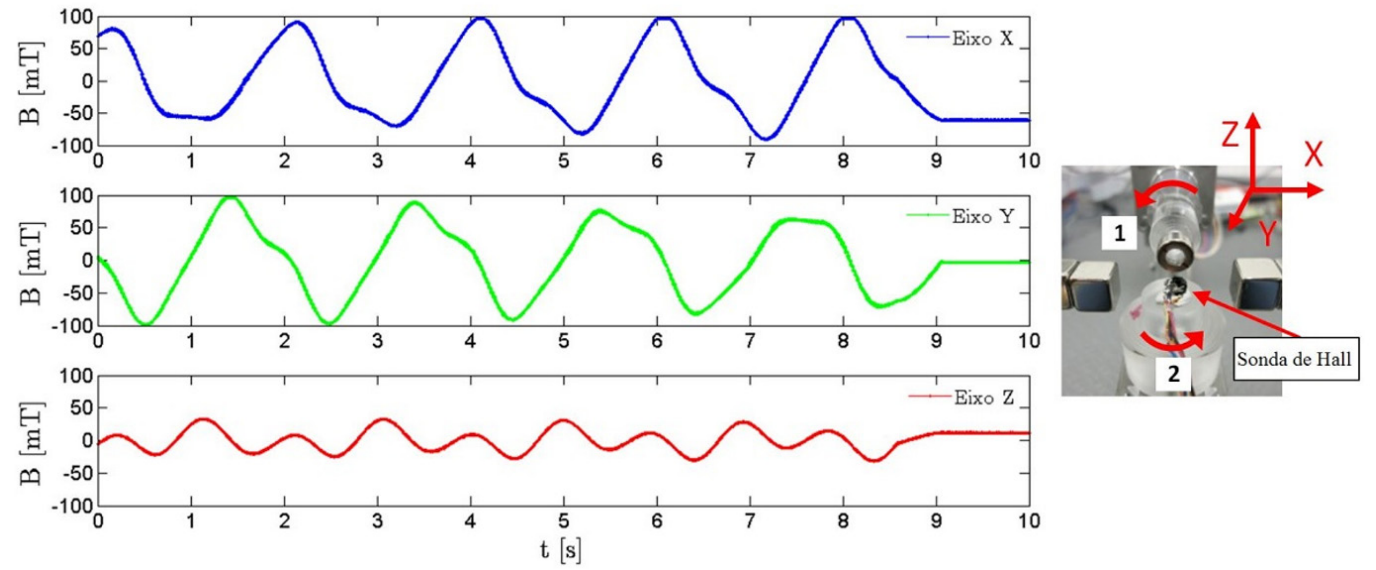

Figura 4. Campo magnético com rotação horizontal e vertical - Íman Nd. Legenda: 1) Rotação do campo magnético no plano vertical, 2) Rotação do provete no plano horizontal.

Pode verificar-se que a densidade de fluxo magnético apresenta valores da ordem de $\pm 100 \mathrm{mT}$ ( \pm 1000 Gauss) para as direcções $X$ e Y, enquanto na direcção $Z$ a densidade de fluxo magnético foi de $\pm 40 \mathrm{mT}$ ( \pm 400 Gauss). As células utilizadas neste estudo foram células de Rhodococcus erythropolis DCL14, que por crescerem em $n$-hexadecano como fonte de carbono apresentam um potencial zeta positivo [2].

\section{Resultados e Discussão}

\subsection{Ensaio com líquidos penetrantes no padrão tipo 1 ISO 3452-3}

Foram produzidos diferentes provetes com defeitos artificiais do tipo micro indentações, de acordo com o procedimento descrito em [1], tendo em vista avaliar a sensibilidade dos LP nestes defeitos comparativamente aos defeitos presentes no bloco padrão Tipo1 ISO 3452-3, que é composto por vários defeitos artificiais com espessura e profundidade de aproximadamente $0,5 \mu \mathrm{m}$ e $10 \mu \mathrm{m}$, respectivamente. O bloco padrão consiste num substrato em bronze, revestido com uma camada de crómio-níquel com $10 \mu \mathrm{m}$ de espessura, que após traccionado longitudinalmente apresenta fissuras segundo a direcção transversal. 
Os ensaios com o método de LP foram realizados de acordo com procedimento especificado na norma ISO 3452-2. De acordo com a norma ISO 3452-1:2013, o penetrante fluorescente usado corresponde a um penetrante do Tipo 1, tendo o excesso sido removido com água (A) e a revelação com pó seco (a), correspondendo a uma sensibilidade de Nível 2. Verificou-se que, apesar de os defeitos padrão Tipo 1 ISO 3452-3 serem facilmente detetados (Figura 5a), não foi possível identificar qualquer defeito na superfície dos provetes com micro indentações (Figura 5b). Este resultado ilustra a dificuldade de detetar este tipo de defeitos, conforme referido na introdução.

\subsection{Ensaio com CB no padrão tipo 1 ISO 3452-3}

A nova técnica de END baseada na utilização de células bacterianas ( $C B$ ) foi também testada nos defeitos presentes no bloco padrão Tipo1 ISO 3452-3, tendo em vista uma comparação directa com o método de END por LP. Os ensaios foram realizados apenas com a deposição das CB R. erythropolis com potencial zeta positivo sobre a superfície, sem recurso a campos magnéticos. Os resultados mostram que as CB coradas com Syto 9 (fluoróforo da Molecular Probes, Invitrogen), que Ihes conferiu a cor verde, alinharam-se no interior dos defeitos permitindo um óptimo contraste entre os defeitos padrão e a superfície que permaneceu negra sob a luz fluorescente (Figura 6).

\subsection{Liga de titânio grade $\mathbf{5}$ soldada por laser}

Foi inspeccionado um provete de titânio com aproximadamente $1 \mathrm{~mm}$ de espessura, contendo dois pontos de soldadura laser pulsado, com cerca de $700 \mu \mathrm{m}$ de diâmetro, com o objectivo de detectar eventuais fissuras resultantes do processo de soldadura. Os ensaios foram realizados por simples deposição das bactérias sobre o provete, sem recurso a campos magnéticos. Os resultados dos ensaios são apresentados na Figura 7 e mostram que as CB permitiram identificar a existência de fissuras radiais no centro dos pontos de soldadura, bem como a rugosidade superficial da região que as delimitava e que eram imperceptíveis a olho nu. O ensaio com a nova técnica de END com CB possibilitou, assim, a identificação de defeitos reais inicialmente desconhecidos e, portanto, não caracterizados. Deste modo, foi verificada a validade da técnica para a detecção de defeitos para uma morfologia que não a dos defeitos padrão, com uma área de abertura para a superfície muito reduzida.

\subsection{Ensaio na liga INCONELTM 9095}

Uma vez que a técnica de END com células CB proposta depende da interacção das bactérias com os materiais, têm sido testados materiais com diferentes composições

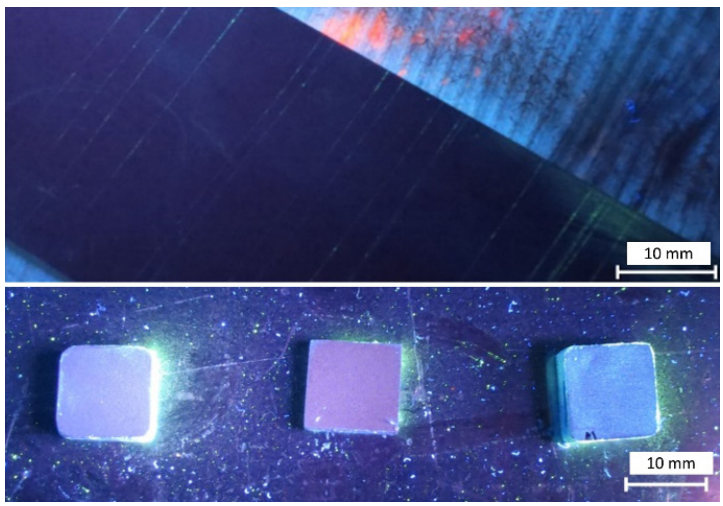

Figura 5. Ensaio com técnica de END com LP. (a) Ensaio no bloco padrão Tipo1 ISO 3452-3. (b) Ensaio em provetes com micro indentações produzidas de acordo com [1].

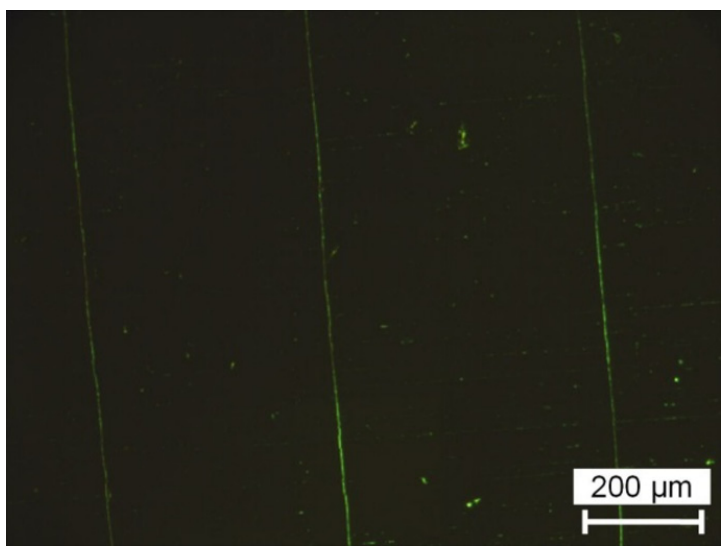

Figura 6. Ensaio com células bacterianas (coradas a verde) no Padrão Tipo 1 ISO 3452-3.

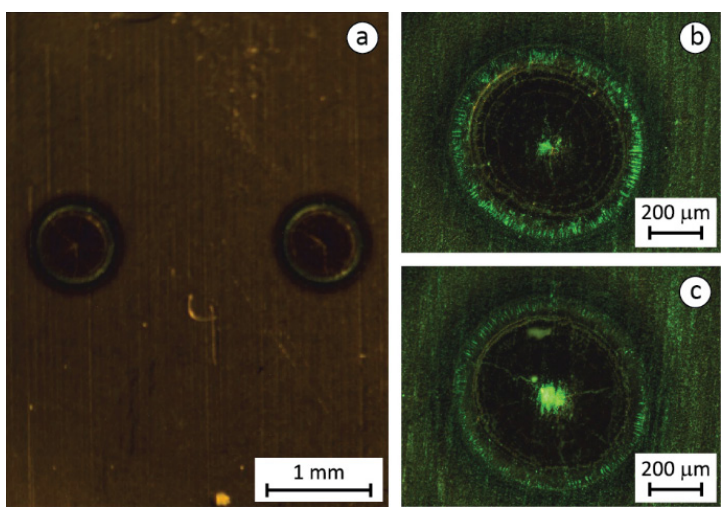

Figura 7. Ensaios em pontos de soldadura laser pulsado em Ti. a) Pontos de soldadura laser; b) Detalhe do ponto \#1; c) Detalhe do ponto \#2. 
químicas utilizados industrialmente. Neste caso, foi testada uma liga INCONEL ${ }^{\mathrm{TM}}$ 9095, utilizada numa peça para a indústria aeronáutica, na qual foram produzidos micro defeitos com um indentador Vickers na superfície previamente polida, de acordo com o procedimento descrito em [1]. O ensaio foi realizado com a deposição de $\mathrm{CB}$ durante 4 minutos, tendo sido removido o excesso após esse tempo. Verificou-se que foi possível detectar todos os defeitos da matriz (Figura 8), tendo os menores defeitos (assinalados a vermelho) uma largura de 2,93 $\mu \mathrm{m}$ e uma profundidade de 0,59 $\mu \mathrm{m}$.

\subsection{Ensaio em ouro com Nano Indentações}

Para avaliar o limite de detectabilidade desta nova técnica foi testado um provete contendo uma matriz de nano indentações num provete de ouro de 24 quilates. A matriz foi produzida com um indentador Berkovich, que consiste numa pirâmide de três lados com um ângulo de $65.3^{\circ}$ entre as três faces e o eixo vertical. Foi seguido o procedimento de ensaio utilizado para a medição de propriedades mecânicas à nanoescala, aplicando cargas entre 125 e $50 \mathrm{mN}$ com uma distância entre indentações de $25 \mu \mathrm{m}$.

Foram depositadas células de $R$. erythropolis sobre o provete durante 4 minutos. Após o tempo de penetração, o excesso foi removido mecanicamente com um toalhete e a matriz de defeitos observada em microscopia óptica com luz fluorescente. Todos os defeitos foram revelados, indicando que as células coradas foram capazes de entrar em todos os defeitos produzidos (Figura 9). Para além da detecção de todos os nano defeitos observou-se que alguns riscos com dimensão inferior ao menor defeito da matriz, que tem uma dimensão da ordem de $6 \mu \mathrm{m}$ de lado e $0,7 \mu \mathrm{m}$ de profundidade, foram detetados, salientando uma vez mais o potencial desta técnica na detecção de defeitos nanométricos.

\subsection{Ensaio em alumínio Anodizado}

Dos ensaios anteriormente descritos, resultou evidente que esta nova técnica END com células bacterianas permite a caracterização de superfícies. Este ensaio visou avaliar a possibilidade da técnica para o controlo da qualidade de superfícies, nomeadamente no controlo da variação da rugosidade superficial.

Foi realizado um ensaio num provete de alumínio da série $2 x x x$ anodizado e com micro indentações Vickers para avaliar a interacção das células bacterianas com uma superfície anodizada. Na Figura 10a é apresentada a imagem obtida antes do ensaio onde é difícil observar alguma irregularidade da superfície, enquanto na Figura 10b é apresentado a imagem da mesma área após o ensaio com CB. O posicionamento das células na superfície revelou a sua real topografia para além de permitir detectar os micro defeitos produzidos na superfície.

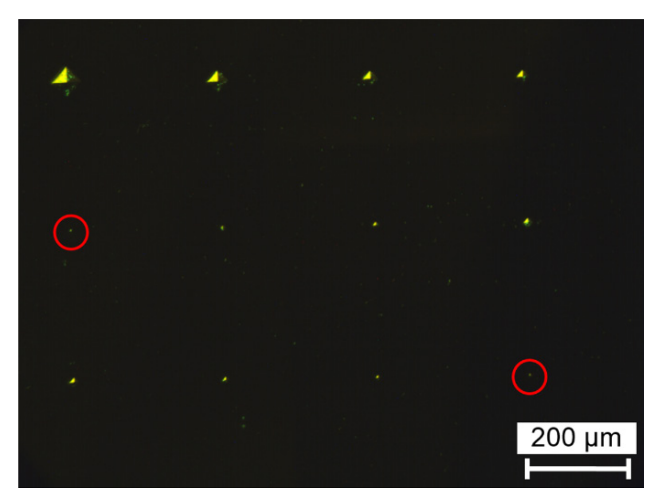

Figura 8. Ensaio num provete em INCONEL ${ }^{\mathrm{TM}}$ 9095 com micro indentações.

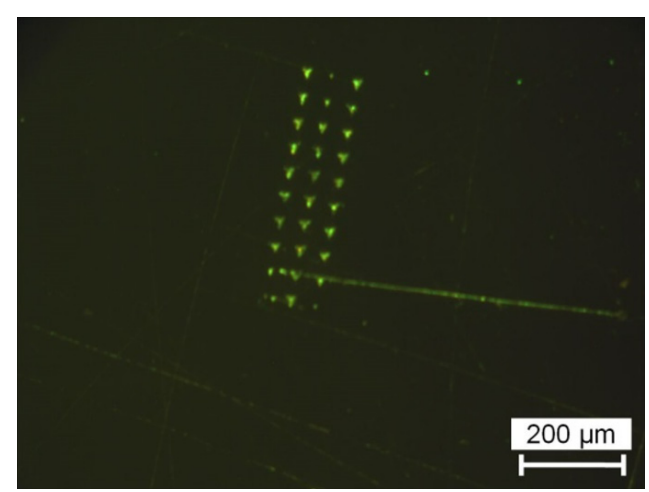

Figura 9. Ensaio em provete de Ouro com nano indentações Berkovich.
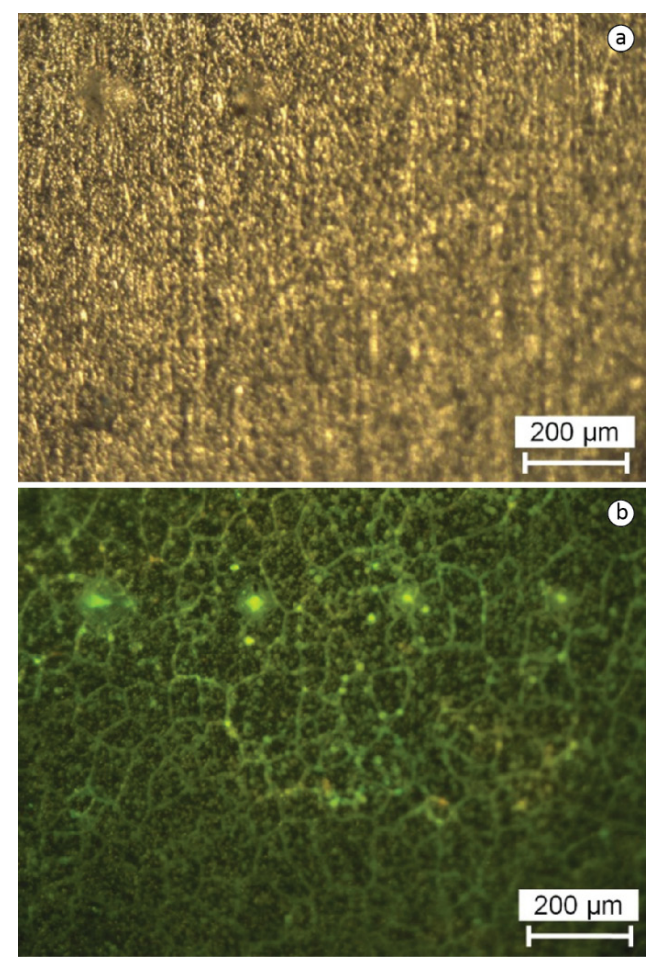

Figura 10. Ensaio num provete de $A A 2 x x x$ anodizado com micro indentações. 


\section{Conclusões}

Do trabalho efectuado foi possível concluir que:

- A técnica desenvolvida é viável e reprodutível, permitindo detectar micro defeitos superficiais numa vasta gama de materiais, incluindo defeitos nanométricos.

- A técnica é sensível ao estado do acabamento da superfície permitindo assim revelar regiões de diferentes topografias.

- Comparando com os LP, a nova técnica de END identifica os defeitos do bloco padrão Tipo 1 ISO 3452-3 com um bom contraste relativamente à superfície envolvente.

- Conseguiu-se detectar defeitos com profundidades nanométricas difíceis de identificar por LP, uma vez que estas se baseiam na capilaridade do líquido e é o volume do defeito que determina a sua detecção.

Demonstrou-se assim a viabilidade desta técnica e o seu grande potencial para revelar defeitos em peças obtidas por microfabricação.

\section{Agradecimentos}

Os autores agradecem à Fundação para a Ciência e a Tecnologia (FCT, I.P.), pelo suporte financeiro concedido a este trabalho no âmbito do projecto I\&D MicroBac (PTDC/EME - TME/ 118678/2010). TS e RM agradecem o apoio concedido ao UNIDEMI no âmbito do Programa Estratégico FCT, I.P. com a referência: UID/EMS/00667/2013. CCCR de Carvalho agradece à FCT, I.P. o apoio no âmbito do programa "Investigador FCT 2013" (IF/01203/2013/ CP1163/СT0002).

\section{Referências}

[1] Santos TG, Miranda RM, Carvalho CCR. A new NDT technique based on bacterial cells to detect micro surface defects. NDT \& E International. 2014;63:43-49. http://dx.doi.org/10.1016/j.

[2] Carvalho CCR, Wick LY, Heipieper HJ. Cell wall adaptations of planktonic and biofilm Rhodococcus erythropolis cells to growth on $\mathrm{C} 5$ to $\mathrm{C} 16 \mathrm{n}$-alkane hydrocarbons. Applied Microbiology and ndteint.2014.01.006 Biotechnology. 2009;82(2):311-320. http://dx.doi.org/10.1007/ s00253-008-1809-3. PMid:19096838. 